\title{
Los bogas del Chocó: un análisis etnohistórico en la dinámica cultural afrocolombiana
}

\section{The bogas of Chocó: ethnohistoric analysis in the Afrocolombian cultural dynamics}

\section{Luz América Lozano Mayo1, Luis Eustorgio Palacios²}

\section{Resumen}

Todos los pueblos han tenido personajes que contribuyeron históricamente al desenvolvimiento cultural de manera evolutiva, asi todos no posean reconocimiento, pues hay algunos que no son tenidos en cuenta aún cuando hayan contribuido desde los más bajos estratos en las consideraciones elitistas; el boga en el departamento del Chocó es víctima de estas circunstancias. Pero en el ámbito del desempeño de su difícil labor, cobra reconocimiento inconmensurable frente a sus benefactores; en definitiva el boga es: fe, confianza, esperanza y determinativo en las circunstancias de vida entre lo bueno y lo malo sobre todo lo relacionado con las noticias y las albricias. El sol y el agua han curtido estos personajes del ayer y de hoy, los cuales están relacionados en los distintos aconteceres históricos del hombre chocoano, porque su razón de ser que son los turbulentos rios como el Atrato, San Juan, Baudó, Andagueda, Tamaná, entre otros. Su champa, su palanca, su canalete y el mate de achicar, testifican el diario trasegar de su existencia. En el período colonial, los ríos de la región del Pacífico, especialmente aquellos donde existen reales de minas, tuvieron gran importancia en la economía de la región y del mundo, porque fueron utilizados para el tránsito desde una provincia a otra y al interior de las provincias, en este sentido, el aporte de los bogas como fuerza humana para la movilización de los esclavistas de un lugar a otro de la geografía regional y nacional, fue de gran significación.

Palabras clave: Canalete, Champa, Mate de achicar.

\begin{abstract}
All peoples have had characters who contributed historically to the cultural development of evolutionary manner, so all do not have recognition, as there are some that are not taken into account even if they have contributed from the lower strata in the elitist considerations, the vogue in the department Choco is a victim of these circumstances. But in the field of performing their difficult task, acquires immeasurable recognition against their benefactors, ultimately the vogue is: faith, trust, hope and determinative in the circumstances of life between good and bad especially related news and good news. The sun and water have weathered these characters of yesterday and today, which are related to the different historical events of chocoano man. As its reason to exist are the turbulent rivers as rivers as Atrato, San Juan, Baudó, Andagueda, Tamaná, among others. His hut, his stick, his paddle and bailing mate, witness the daily decanting of its existence. In the colonial period, the rivers of the territory Pacific region, especially those where actual mine the-
\end{abstract}

1 Antropóloga. Investigadora Principal del Componente Sociocultural del Instituto de Investigaciones Ambientales delPacífico(IIAP), Quibdó, Colombia. e-mail: alozano@iiap.org.co

2 Etnobiológo. Contratista investigador adscrito al componente Sociocultural del Instituto de Investigaciones Ambientales del Pacífico (IIAP), Quibdó, Colombia.

e-mail: eustorgio1956@hotmail.com

Recibido: 22 de enero de 2013

Aceptado: 29 de marzo de 2013 


\section{Bioetnia Volumen 10, 2013}

re, had great importance in the economy of the region and the world as were used for transit from one province to another and within of the provinces in this regard, the contribution of the oarsmen as human force for mobilizing the slavers from one place to another of the regional and national geography, was of great significance.

Keyword: Canalete, Champa, Matte shrink.

\section{Introducción}

Durante los siglos XVI, XVII y XVIII las potencias europeas gestaban procesos de invasión para que en forma competitiva, ejercer dominios sobre territorios ajenos a los suyos, como es el caso invasor de España y otros países en la Nueva Granada.

El espíritu colonizador con el propósito de fortalecer imperios de riguroso dominio entre sus contrincantes, realizó distintas expediciones a un nuevo continente que en el trasegar de la historia fue dominado por Hispanoamérica. Aquí confluían los habitantes primarios de regiones confusas y difusas en los procesos de comunicación derivados de poco intercambio comunicativo, dada las enormes distancias que los separaban desde su origen selvático en relación con la posición limítrofe de sus connaturales, sin embargo, es propicio señalar que la necesidad de intercomunicación de los seres humanos, rompe barreras y distancias imponiendo la satisfacción de sus necesidades básicas y primarias a través de una necesaria comunicación o interlocución del hombre con el hombre.

El primer establecimiento de comunicación directa que se establece en la "América española", es la que se produce a través de los choques culturales producidos por las distintas etnias indígenas que históricamente trasegaron las diversas márgenes de los diferentes ríos que pueblan al departamento del Chocó.

El boga en el Chocó es una semblanza de la cultura histórica que está representada incluso en canciones, tal es el caso de la canción referida al "tío guachupecito", personaje de características longilineo, alto, delgado y con prominencias jorovescas, quien conduciendo su champa por las riveras del San Juan, en una de sus orillas encuentra a un núcleo de niños (quienes como es costumbre en el Chocó denominan tío o tía a los mayores), consideran estos que el boga viene cansado del cumplimiento de sus distintas travesías y compadecidos de él al compararlo con uno de los peces más apetecidos de la región: "El guachupe", lo invitan a reunirse con ellos para que descanse del trajín de sus labores, al verlo tan escuálido y cansado. Por esta razón le dicen: "Tío guachupecito siéntese, siéntese... a lo cual el responde: paraíto nada más sobrino, paraíto nada más”.
Pues el tío guachupesito no se considera cansado porque las exigencias de ser boga en los distintos ríos lo han adoctrinado y llenado de fortalezas, que no le permiten descanso alguno hasta cumplir su itinerario y dar razones de las tareas que le han sido encomendadas.

De todas maneras, los bogas en el departamento del Chocó han cumplido una misión histórica y contribuido desde su conocimiento y sus prácticas al engrandecimiento de los distintos pueblos y con el sabio conocimiento de sus ríos hicieron travesías con pasajeros, cargas y mensajes para los pobladores de esta región.

Por esta razón la infausta situación por la que atravesaron y atraviesan les trae recordaciones de su pasado ancestral en donde se tejieron liturgias, carnavales paganos, contentos y alegrías al reunirse con sus conocidos, amigos y familiares. Por ello en el recorrido de las distancias sin descanso entonan canciones que aligeren el paso, tal como: "canalete boga, boga, boga ligero pa yo llega, boga ligero payollega. Canalete de chachajo me lo regaló mi padre...”.

Por ello es importante develar qué es, quién es y qué ha sido el boga en el acontecer histórico del desenvolvimiento de la tradición cultural y social que hoy ha alcanzado este departamento rescatando a uno de sus personajes más recónditos y que no han sido tenidos en cuenta en los avances que hasta hoy se han logrado.

\section{Método}

Como aspectos generales de la investigación se debe destacar la revisión de la información secundaria existente en los diferentes centros de información consultados a fin de determinar los orígenes históricos sobre los cuales se soporta el papel fundamental que jugaron los bogas en la navegación fluvial especialmente en los siglos XVI y XVII en el río Magdalena.

Se sumaron a este esfuerzo investigativo todas aquellas personas conocedoras del tema, quienes nos facilitaron la información a través de charlas informales, entrevistas prolongadas, conducentes a la recolección de historias de vida de determinadas personas, trabajo detallado con informantes claves, que fueron fundamentales en el diálogo interdisciplinario que arrojó gran parte de la información.

Es necesario mencionar también como elemento central en la metodología, los viajes que se hicieron a diferentes sitios de la región en la búsqueda de estos bogas elementos centrales del presente trabajo investigativo. En el mismo orden de ideas hay que destacar el decidido apoyo y la total colaboración de los habitantes de las comunidades de Pie de Pató (Alto Baudó), Condoto y Nóvita, sin cuyo concurso las labores no hubieran sido posibles. 


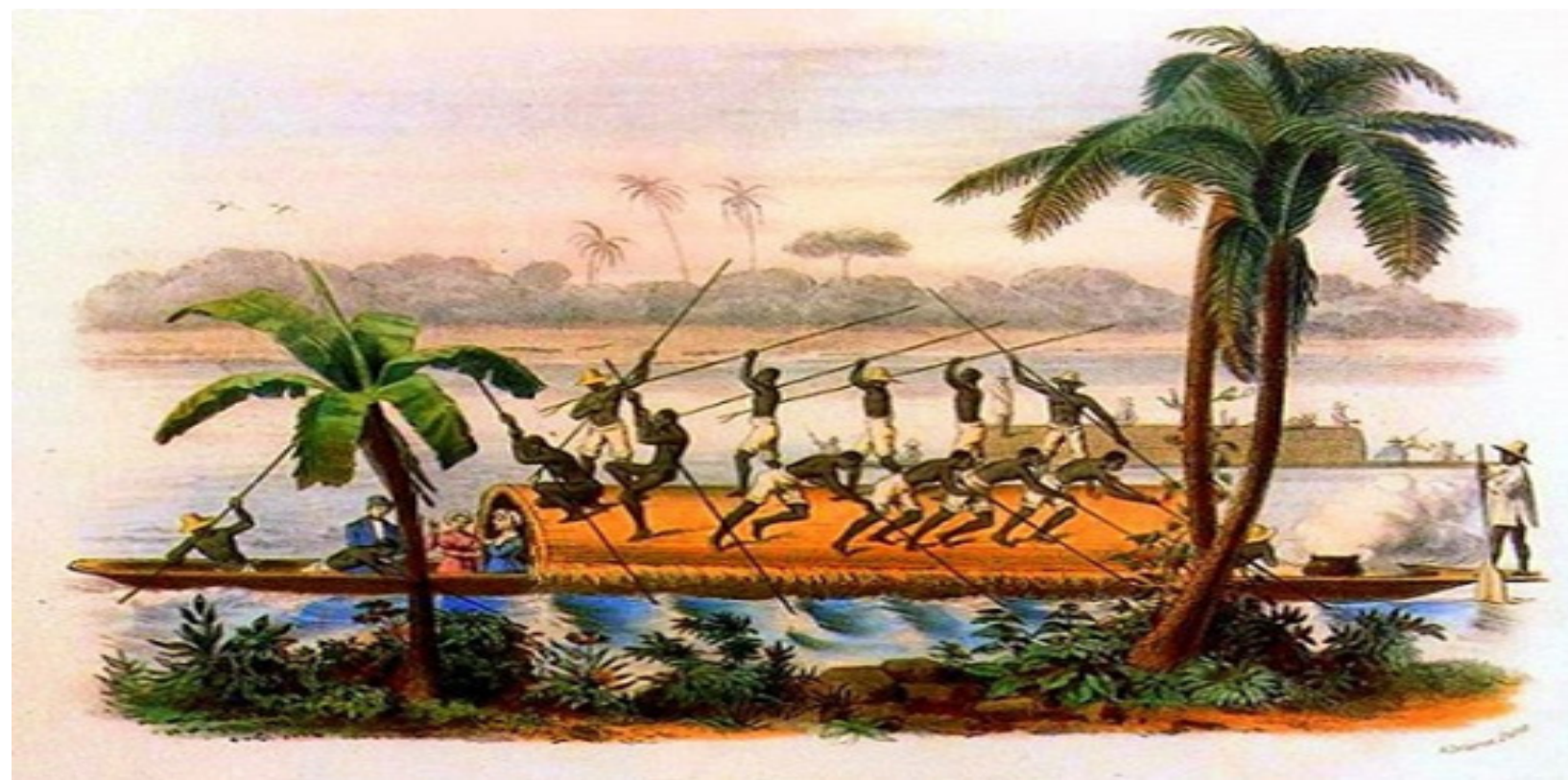

Figura 1. El negro en el trasegar por las diversas márgenes de los ríos.

\section{Resultados}

Durante todo el período colonial, el río Magdalena fue la vía más importante para comunicar a la región andina con el mar Caribe y Europa. La Flota de Indias, que llegaba a Cartagena procedente de España, aprovisionaba los territorios americanos en ropa, aceites, vinos y otras mercancías apetecidas por los españoles residentes en el Nuevo Mundo.

Sin embargo, remontar el río hasta Honda requería pericia y fortaleza. Era un trabajo brutal de doce horas diarias en canoas con catorce bogas que cargaban hasta diez toneladas de peso. En los primeros años de la Conquista los indígenas se utilizaron por los españoles para garantizar el transporte de personas y mercancías, pero, como en la mayoría de las actividades, fueron desplazados por la gente africana y sus descendientes. La fortaleza física y la destreza para esquivar los peligros del río eran cualidades fundamentales de los bogas o navegantes que pasaban sus vidas entre las aguas (Figura 1). La imagen que se tiene de ellos es la de hombres robustos, francos, inteligentes y maliciosos. También se dice que vivían contentos, pues, a diferencia de otros esclavizados, gozaban de permanente movilidad y estaban en contacto con la naturaleza, es decir, llevaban una vida más independiente.

Los bogas fueron recurrentemente visibilizados: decenas de viajeros dejaron plasmada en cartas, relatos e informes, imágenes de sus cuerpos, sus formas de hablar, su trabajo y sus cantos. Esto no quiere decir que reconstruir el pasado de los bogas sea una tarea fácil. Muchas de las fuentes que revelan algo de su vida son huellas construidas no por ellos mismos sino por personajes ajenos a su realidad, son imágenes mediadas por la mirada de los letrados modelados por sus códigos estéticos y morales, por sus nociones de la naturaleza y la cultura, la civilización y la "barbarie".

El boga era admirado por su fuerza física y su cuerpo no dejaba de despertar cierta fascinación, cierto deseo por su exacerbada corporalidad y su fuerza atlética aunque velado por un recato del letrado: "Un boga tenía cada brazo como el de una ceiba, el pecho ancho como el de una piedra de lavar ropa, cada mano como osos y la voz como el ronquido de un toro" decía el escritor y ex-gobernador cartagenero Manuel Madiedo (1973). El cuerpo del boga atraía con cierta distancia al letrado, civilizado y cortés por su falta de manera, de recato y su exagerada animalidad (Samper 1861).

Si bien el boga era apreciado por ser un motor del país, en términos generales era juzgado como reflejo de atraso, en medio de los ideales de progreso y prosperidad material y moral. A mediados del siglo XIX el boga y sus champanes comenzaban a ser vistos como rezagos del pasado frente a los poderosos y modernos buques de vapor.

El papel importantísimo que desempeñaron los bogas en la circulación fluvial de bienes y personas no debería ser minimizado. José María Samper, un intelectual bogotano del siglo XIX al morir, señalaba en 1867 que el trabajo de los zambos y los mulatos colombianos era un factor indispensable para el comercio de la nación: "El hombre de las tierras altas no puede vivir sin pedirle sus productos al mestizo y al mulato de las tierras medianas y los valles profundos" afirmaba Samper, "y tanto uno como los otros obtienen el concurso comercial del zambo y el mulato de las costas sin los cuales no habría navegación ni tráfico 


\section{Bioetnia Volumen 10, 2013}

ninguno". Este autor, no es un buen simpatizante de los bogas, los describía como seres "salvajes e insolentes", pero a pesar de la poca admiración que les guardaba, reconocía la importancia de su labor, sabía que de ellos dependía el transporte de viajeros como él y el intercambio de bienes entre las distintas regiones del país; sabía que en la segunda mitad del siglo XIX, los bogas eran agentes imprescindibles del funcionamiento económico de la nación.

Aunque los bogas a los que nos referimos siempre han sido caracterizado por ser afrodescendientes, en los siglos XVI y XVII, eran hombres indígenas ubicados en el oficio por encomenderos que habían encontrado provecho comercial en la experiencia navegante y pesquera de las sociedades nativas. La boga de los indios, sin embargo, había sido categorizante prohibida por la Corona Española, cuando a finales del siglo XVI se estableció que el arduo trabajo del remaje había traído nefastas consecuencias para la salud, la vida y el alma de los indios y se determinó que estos debieran ser reemplazados por grupos de esclavos negros, considerados, de acuerdo con las creencias inherentes al sistema esclavista, más fuertes y resistentes para las labores físicas. Durante un "tiempo de aprendizaje" aprovechado por los encomenderos para demorar el cumplimiento de las órdenes de la corona, los esclavos habían prohibido las técnicas de la boga de los remeros indígenas de manera que según Aníbal Noguera (1982) para finales del siglo XVII "la tripulación de los formada nativos y negros había terminado definitivamente en manos de los africanos".

Durante los siglos XVI, XVII y XVIII, se había ido presentando además un proceso importante en los poblados a lo largo del río Magdalena: un proceso de mestizaje que en estos territorios podría ser acertadamente "zambaje". De la unión entre los hombres negros y mujeres indígenas, unión recurrente según los viajeros de los siglos XVIII y XIX, los zambos libres eran los protagonistas del boga en el río Magdalena, junto a ellos remaban también negros y mulatos que bien habían sido libres desde su nacimiento o bien eran esclavos liberados mediante algún mecanismo de manumisión. Así, cabe resaltar que el transporte y el comercio por la gran arteria fluvial, era muchas décadas antes de la abolición de la esclavitud, un trabajo realizado por hombres libres; un trabajo arduo, con múltiples riesgos y dificultades pero con unas reglas laborales y sociales muy distintas a aquellas que funcionaban en el sistema esclavista de amos-dueños-esclavos-objetos (Hust 2010).

Teniendo en cuenta estas consideraciones de donde se origina el vocablo boga y para el caso del departamento del Chocó, se encuentra que el ejercicio de estas actividades logra establecer un espectro que circunda históricamente los prolegómenos de las comunicaciones a través del gran imaginario y las inconmensurables virtudes de hombres que lograron aprovechar la indiscutible riqueza de los ríos que conforman este departamento.

Los habitantes de los asentamientos en los distintos villorrios se intercomunicaban a través de los famosos "razoneros" quienes eran los encargados de llevar y traer las noticias, para hacer reuniones en donde se establecían liturgias de ritos, de cantos, de rezos, oraciones, recordatorios de sus dioses, tales como Yemayá, Obatalá, Oyun, Orula, Elegua, Changó y todos los otros Orichas del recordatorio del Panteón de sus dioses.

De tal manera que el boga en el Chocó inicia a convertirse en un personaje de la más alta importancia en el desarrollo social y cultural del poblamiento de los distintos fundos que empiezan a echar raíces en las márgenes de los ríos, quebradas y riachuelos que circundaban esos territorios. La importancia del boga, cobra un valor superlativo en la medida que el crecimiento de los distintos asentamientos van ampliando la estructura de sus familias y la posesión de terrenos para la implementación del trabajo diversificado, entre la minería, la agricultura, la pesca y la cacería.

El desenvolvimiento de estas incipientes comunidades soporta pues un alto avance a través de la comunicación, que tiene un valor agregado, cual es el boga. Este insigne personaje es el portador de todas las noticias buenas o malas: el nacimiento de un niño, la unión de las parejas en los distintos pueblos, el fallecimiento de las personas de distintas comunidades, los beneficios y maleficios causados entre unos y otros, la convocatoria a diversiones como los bailes llevando músicos de distintos lugares, los litigios que se presentaban a nivel intercultural, las intervenciones abruptas de personas ajenas a sus comunidades y la salvaguardia de su etnia cuando se sentía amenazada, por otras. Pero uno de los más importantes papeles que jugaba el boga en estos aconteceres culturales, fue que se constituyó en el transportador de personas, mercancías y portador de las mejores albricias entre todas las comunidades en los inicios del siglo XIX en el departamento del Chocó (Figura 2).

El boga a nivel de la estructura familiar estableció también estratos de linaje, por cuanto no era lo mismo el o los descendientes de cazadores, pescadores, mineros, que provenientes del "comunicador social", quien jugándose la vida y confrontando los más graves peligros y amenazas en que se constituían los torrentosos y turbulentos ríos, las distintas comunidades, fincaban su esperanza en él y esperaban con paciencia que sus dioses lo ampararan en la pertinaz aventura y con el más alto estoicismo, quizás como en la Odisea oraban a sus dioses día a día, semanas tras semanas, meses tras meses, hasta que apareciera el boga trayendo las noticias y las albricias que ellos esperaban.

Estas y otras circunstancias obligaron a que el Estado Soberano del Cauca empezara a pensar en el establecimiento de una comunicación más estructurada y reconocida por la administración pública. Pues hasta ese momento en el 


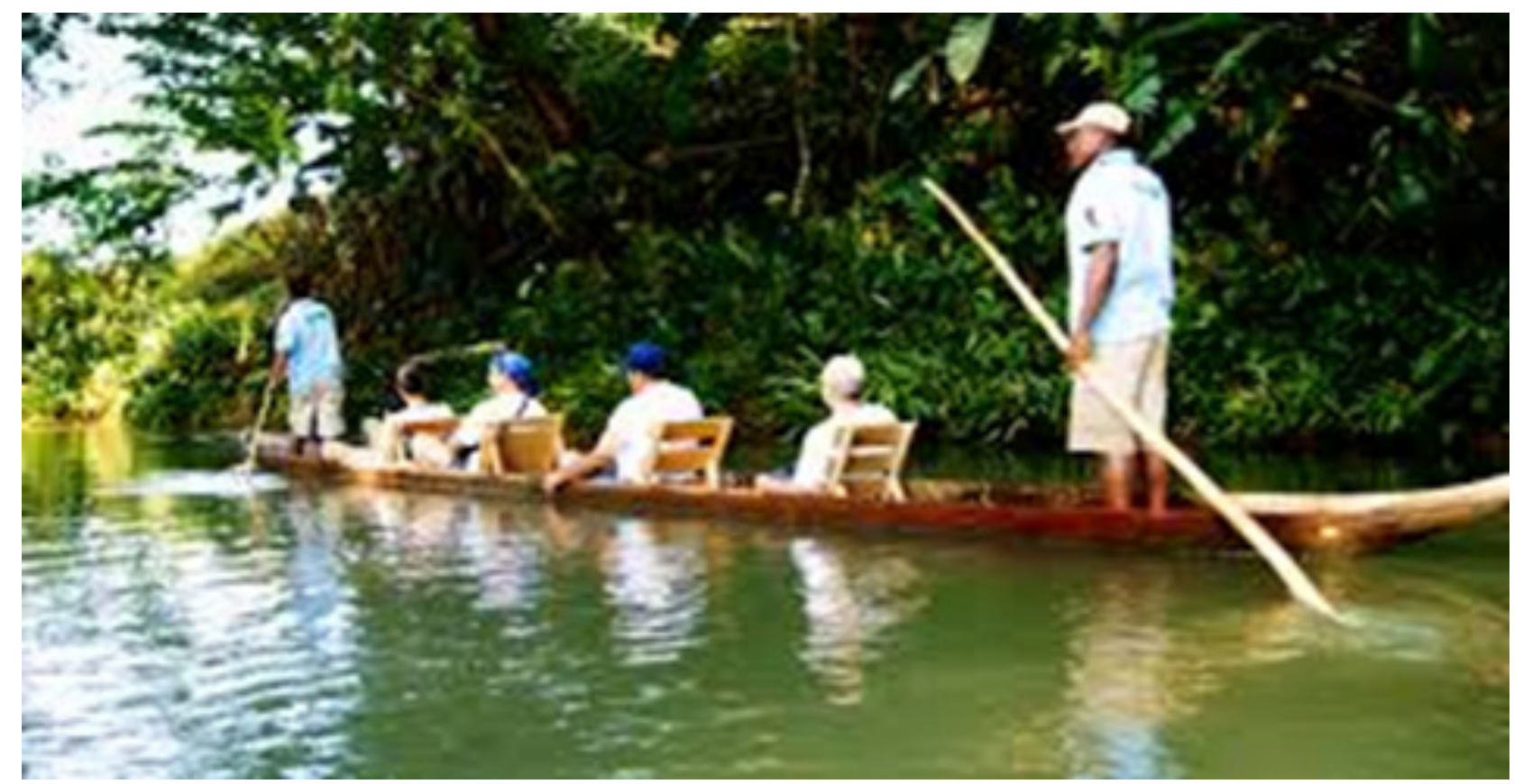

\section{Figura 2. Los protagonistas (el boga) en el río Atrato, junto a ellos remaban también negros y mulatos.}

departamento del Chocó no existía ni siquiera el telégrafo, razón por la cual los bogas tuvieron la oportunidad de ser reconocidos como "correo".

Pero la suerte de estos personajes no siempre fue vista con buenos ojos a nivel regional, porque los mensajes que ellos portaban en ocasiones traían noticias funestas y nefastas en donde se comunicaba la enfermedad, el fallecimiento o alguna desgracia familiar. De esta manera el boga era visto en muchas ocasiones como el mensajero de desgracias personales o familiares.

Sin embargo, cuando los mensajes recibidos hablaban de amoríos, de ajuntamiento de parejas y de matrimonios especialmente, el boga recobraba el status de portador de buenas albricias. De esta manera la catalogación del boga en el Chocó fue determinada con un término regional: "el boga es un indife". Significa que unas veces es bueno (cuando trae las albricias) y es malo cuando trae malas noticias. Es decir, el ejecutor de esta labor vivió siempre entre el bien y el mal con respecto al cumplimiento de las labores encomendadas.

Pero miremos ahora cuáles son los principales elementos que utiliza el personaje de marras: básicamente utiliza una canoa, la que por lo general se usa para transportar mercancías, enseres de distinta índole, pasajeros e indeterminada clase de elementos que ameriten ser trasladados de un pueblo a otro, exigiendo así la fuerza participativa de varios bogas y teniendo en cuenta la bravura torrentosa de los distintos ríos que tenían que enfrentar para lograr el acometido. Sumándole a ello que esta embarcación tiene una variable de entre $10 \mathrm{~m}$ de largo por dos de ancho y es construida por los finos maderables de la flora selvática del Chocó. Siendo que para estos menesteres intervienen aproximadamente 10 personas quienes en filas de a cinco de izquierda a derecha unos son impulsores de la canoa y otros son "cuñadores". Es decir, que teniendo en cuenta los remolinos, los cuñadores son quienes evitan el fuerte oleaje para evadir el hundimiento de la embarcación bien sea a la izquierda o a la derecha. Mientras los otros cinco son quienes imprimen la velocidad de la embarcación, todos ellos utilizando como instrumento la palanca, la cual está proveída en su parte final por una herradura llamada "recatón", que es una especie de horma de hierro para proteger el material maderable del cual está elaborada la palanca.

De otro lado el boga mensajero "el indife" para el cumplimiento de su difícil labor utiliza "la champa" como medio de transporte. Esta tiene dimensiones más pequeñas que la canoa tanto en lo largo como en lo ancho y como elementos impulsores de este medio de transporte utiliza la palanca y el canalete; la palanca dependiendo de la estatura del boga, mide aproximadamente dos metros. Está elaborada por maderables de la flora que reúna las condiciones de durabilidad y no sean muy pesadas. Estas son elaboradas por personas campesinas que conocen también los ríos y son expertos en la construcción de las mismas, después de consultar los distintos trayectos que debe abordar el ya mencionado boga indife.

El otro instrumento que complementariamente debe utilizar el boga es el canalete (que en la mayoría de las 


\section{Bioetnia Volumen 10, 2013}

veces era de chachajo, el mate achicador que sirve para sacar el agua que se introduce en la canoa al enfrentar las difíciles corrientes que le toca sortear.

Cabe añadir que estos elementos aun cuando son diseñados y elaborados por verdaderos personajes que saben y conocen a ciencia cierta su oficio, no son autóctonos de la región chocoana; son réplicas traídas desde el continente africano en el siglo XVI cuando se origina la conquista negroide y es trasplantada al continente americano y adoptada en el departamento del Chocó por los esclavos como medios y usos en el desempeño de diversas actividades, y entre ellas, especialmente la minería.

Antropológicamente se debe afirmar que estas réplicas obedecen a una herencia cultural, porque para los primeros momentos de asentamiento del hombre africano en América, no existió otra escuela que la tradición de saberes: unas veces por el consagrado aprendizaje del hijo con respeto al conocimiento de su padre y con el propósito de reemplazarlo en el conocimiento de sus tareas y en otras ocasiones por las exigencias e imposición de los esclavizadores, quienes suponían que los hijos de los bogas habían aprendido el trabajo de sus padres, lo cual los obligaba a reemplazarlos cuando eran considerados inútiles para las labores mineras y de bogas, siendo este el menester propicio de la escuela tradicional.

De esta manera se puede sostener que los bogas son una historia viva en el Chocó, aún cuando no están organizados en una asociación, la tradición de antaño no se perderá mientras exista la riqueza diversa de sus indistintos ríos que facilitan aun con riesgos y peligros la comunicación acuática que no posee este departamento a nivel aéreo y terrestre, siendo que los ríos fueron y siguen siendo el primero y más utilizado medio de comunicación por encima del terrestre y aéreo. A la vez que las comunidades rurales aún expuesta a las súbitas avenidas de sus ríos, no posee otra esperanza de comunicación, de venta de sus escasas cosechas, intercambio cultural y sobrevivencia en general, que el mayor recurso que le brinda el boga para el desarrollo de la pertinencia de todas sus actividades, en la obligatoriedad de persona social y de reconocimiento en la interactividad con sus congéneres de otras regiones.

En los 31 municipios que conforman el departamento del Chocó, han existido bogas de mucho renombre. Por ejemplo, en el municipio de Quibdó, aún cuando no fue posible establecer el nombre de sus progenitores, de un momento a otro aparecieron en esta localidad quienes venidos del bajo Atrato, se presentó un dueto a quienes solo se les reconoció el apodo o remoquete de "Papá Juan y Pachanga". Personajes estos que con figura quijotesca el primero, quien con configuraciones similares al ya descrito tío guachupecito, desertó del oficio de boga para dedicarse a oficios varios en compañía de su compinche Pachanga. Se hicieron famosos en esta capital preconizando y ofreciendo facilidades para proveer a distintos hogares de la localidad, que a falta del acueducto ofrecían tanques proveedores del vital líquido y argumentaba venderlo a sus compradores vacíos o repletos de agua. Pachanga era brevilíneo y de una fuerza inusitada, y en compañía de su compinche y a través de las indistintas pilatunas cometidas, terminaron conminados en prisión.

Se colige, se infiere y se deduce que quienes abdican al complejo mundo de los que prestan el valioso servicio de bogas para dedicarse a labor alguna que afrente tan alta dignidad, cae en desgracia.

Consecuencialmente, en Istmina (segunda ciudad en importancia en el departamento del Chocó), existieron muchos bogas para atravesar las distintas arterias fluviales de algunos de los ríos ya mencionados con antelación; uno de los más grandes reconocidos, fue el famoso 19, porque le faltaba un dedo en su mano derecha, pero esto no era un obstáculo para manejar con pericia su champa hasta las bocas del San Juan, razón por la cual la Compañía Minera del Chocó Pacífico lo nombró "mensajero".

Lo referido en este artículo que se relaciona con los bogas sobre todo del departamento del Chocó se constituye en un documento de lo que ha sido y es parte de la historia sociocultural de su desarrollo político y económico.

Estos hombres construyeron un estándar de vida que recorrió y todavía recorre millares de kilómetros acuáticos con la intención de intercomunicación con el propósito de desarrollar a las distintas comunidades que no tienen comunicación, en los mayores estándares de vida de la ciencia y la tecnología. Los bogas del departamento del Chocó construyeron una historia especial que en el trajinar de la suprema bravura de sus distintos ríos, no solo construyeron el establecimiento de tipo comunicativo y comercial, sino que se hicieron también responsable con todos los riesgos posibles ávidos y por haber transportado a altísimas personalidades del país en el intento y procura de sus hazañas políticas como es el caso del extinto Presidente de la República Marco Fidel Suárez y su señora quienes recorrieron parte de las riberas del río San Juan a palancasos del ya mencionado boga conocido como "19".

Este Presidente al visitar a la segunda ciudad en importancia del departamento del Chocó, capital Istmina, nombre derivado de la histórica explotación minera, su nombre real es Istmo de Minas, la declaró como ciudad bonita y amable. Sin embargo, hizo también un alto reconocimiento a los hombres negros del Chocó que no solo derivaban su vida a través de la minería tradicional, sino también del alto esfuerzo que él reconoció que hacían los bogas en el confrontamiento de las turbulentas aguas, de la bravura de los ríos que conforman al departamento del Chocó.

En el caso del municipio de Condoto surgieron bogas 


\section{Los bogas del Chocó. LA Lozano, LE Palacios}

de la talla de el gran Casildo y el famoso Juvenal, quienes se recorrieron el río Condoto, San Juan, Iró, Tamaná, Tajuato, entre otros y lo hacían de norte a sur y de oriente a occidente con estudiantes y comerciantes de estas regiones.

Bogas estos que por su tradición en el ejercicio de su labor fueron confrontados por la necesidad de sus servicios ante un pueblo que favorecía más los beneficios del uno y del otro. Aquí se discutía públicamente la experticia del buen boga que tenía más experiencia en el recorrido de las aguas que dificultaban el transporte primario de todos los pueblos del departamento del Chocó.

Mientras que en Baudó son destacados los nombres de Juan Evangelista Rodríguez, Abelino y José María, quienes brillaron por su pericia y dedicación, Juan Evangelista experto trajinante del Alto, Medio y Bajo Baudó, quienes impusieron su ley en contra de la bravura de este río, destacándose como verdaderos bogas con heroísmo histórico, que se constituyeron en personajes emblemáticos de las distintas regiones reseñadas por la agresividad fluvial que caracteriza al departamento del Chocó.

Pie de Pató, municipio de Alto Baudó, Chocó, Colombia.

Entrevista con el señor Juan Evangelista Rodríguez

Nació en Certeguí, Chocó.

Edad: 87 años

Padre: Ángel Saturio Rodríguez

Madre: Baldoina Palacios

El señor Juan Evangelista, conocido en Pie de Pató como Juan Pospó, inicio el diálogo de la siguiente manera: Yo fui boga, yo le viajé a las más gentes aquí en Baudó; le viajé al señor Félix Cantalicio Romaña, le viajé al Antonio Salguero, un señor Manuel Ramos, al señor Daniel Abadía al finado Hortensio Palacios, le viajé al finado Rómulo Palacios. Durante muchos años, viajé de Baudó a Quibdó y de Quibdó a Baudó, a palanca y canalete; de bajada a canalete y de subida a palanca (Figura 3).

Todo baudoseño que pasaba carga por este camino,

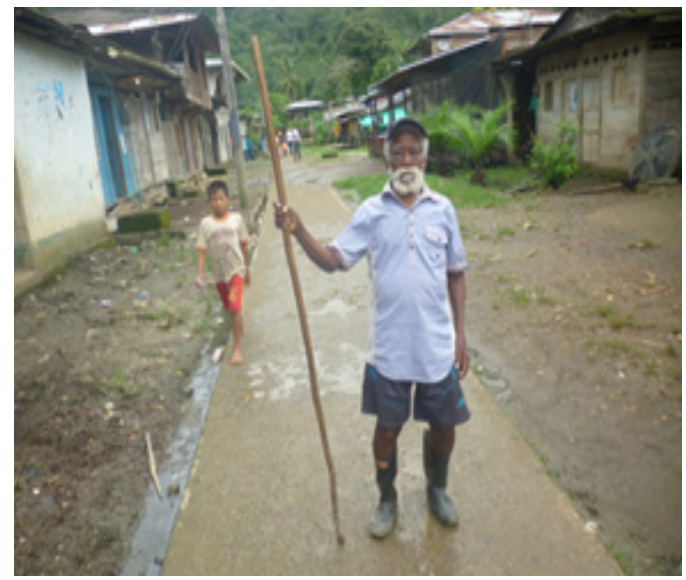

Figura 3. Juan Evangelista boga de reconocida trayectoria en Pie de Pató. viajaba en piraguas, champas o canoas, en las que cabían entre 20 y 25 bultos de arroz, cacao y caucho, aquí hubo una cauchería y llegó mucha gente de otra parte, subían al palo con espuela.

Había canoas que metían tres bogas y otras que metían dos, según el tamaño; muchas canoas las pasaban de este lado, las metían por el camino, el camino por donde las pasaban en algunos lugares ya se ha derrumbado y la gente ya no pasa por allí. El cuidado de las canoas en el pie del camino en la orilla del río Pató, estaba a cargo del señor Juan Domingo Hinestroza, el papá de Abelino, él era el que cuidaba las canoas y la carga, allí en su casa en la cabecera del río Pató. Por este camino también pasaban cerdos, los señores Daniel Abadía, José del Carmen y Guadalupe, llevaban muchos cerdos para Quibdó por este camino.

En los viajes de Píe de Pató a Quibdó, cuando el río no estaba grande, se llegaba en 2 días; hacíamos la estación de Apartadó para abajo, en un sitio llamado Chiguarandó, muchos tipos les gustaba dormir donde mi mamá, ella atendía muy bien a la gente, se levantaba a hacerles su fiambre. En Boca de Apartadó, vive el señor Tillo, la señora Baldomera, era otra persona muy amable, ella vivía en el charco hablador; uno decía adiós y el charco contestaba adiós... Uno salía de Chiguarandó o de Boca de Pató y llegaba a Quibdó; allá arrimábamos donde una señora Sofía Mante, donde el señor Raúl Cañada, donde Celedonio y su señora Jovita, los compradores de arroz venían a comprar a la orilla del río Atrato; otras veces, los dueños de la carga alquilaban piezas y vendían su carga al señor Epifanio Álvarez y a Adriano Rivas; Crescencio Maturana era otro comerciante, él era de Lloró. Los bultos de chocolate y de caucho los llevaban donde el yerno de Moncada y los vendían. Moncada tuvo una trilladora aquí en Pie de Pató y otra arriba en Santa Rita.

Cuando llegué aquí a Pie de Pató, conocí la casa de Julio Mejía, también había un lugar que se llamaba el comisariato, allí llegábamos a vivir todos los foráneos; yo llegué a cargar, yo era pasero aquí en la loma. Otros bogas fueron: Abelino, José María y otros. Desde Istmina, venía gente a pasar carga aquí a Pie de Pató. Vinieron otros hombres como Griseldino, José Ángel e Indalecio Urrutia, este señor pasaba el camino con dos bultos en la espalda tocando una flauta.

También viajé de boga por la ruta de Yucal-Suruco-Munguidó-Quibdó, el responsable de la bodega allá se llama Abelino; él todavía está vivo, por esa ruta también se hacia el viaje en 2 días. Según dijo uno de los amigos del señor Juan Evangelista, él fue uno de los mejores bogas del Baudó: "Él fue de los mejores bogas, porque él cuidaba mucho la carga, la gente le tenía mucha confianza".

Yo me iba y venía con mi champa llena de estudiantes, todos esos muchachos y muchachas los traía yo desde 


\section{Bioetnia Volumen 10, 2013}

Quibdó; a la policía también le hice viajes, los traía y los llevaba, ellos también confiaban mucho en mí, en mis viajes con Feliz Cantalicio Romaña, yo traía negocios para venderlo aquí en Pie de Pató, él me autorizaba a comprar mi quintal de queso.

Cuando viajábamos nos amanecíamos, especialmente cuando la luna estaba bonita, cuando no crecía, pero cuando crecía nos quedábamos en la orilla; también fui montará, cuando no viajaba cazaba muchos animales en la selva, cazaba pava, pavón, perico y otros. Yo tuve una hija, se llama María Yasney, ella vive en el Valle Chocó.

El señor Rogerio Díaz dijo: "De los bogas antiguos, el único que hay vivo es Juan, es muy buena persona, como boga, fue excelente, a mí también me hizo viajes, Juan Pospó, sí, yo le decía azucarita, por sobrenombre".

El señor Miguel Ángel Cabrera Palacios dice: "Juan fue uno de los mejores bogas, porque él cuidaba mucho la carga; es muy buena persona y en El Baudó con todo el mundo se ha portado bien, como boga fue un tipo honrado, no tocaba lo ajeno, se mantuvo del sudor de su frente."

Personaje: Juan Bautista (Robálo)

Falleció a edad de $90 \ldots$ años aproximadamente

Narrador: Luis Neo Palacios Sánchez (84 años)

El boga más sonado fue Róbalo. Lo conocí cuando yo era niño, según él me vio nacer allí en Guineal, dice Luis Neo. Róbalo era un hombre negro, alto, acuerpado, era muy amable y amigable con todo el mundo.

El primer patrón de Róbalo, fue Segundo Ramírez, agricultor que tenía unos cultivos muy grandes, él vivió toda su vida de criar marranos, sembrar arroz, plátano y maíz. El señor Segundo Ramírez, llevaba cerdos a vender a Istmina, llevaba entre 40 y 50 cerdos, los criaba y engordaba en varias etapas, tenía su finca en Dubaza, los terrenos estaban ubicados al frente de Puerto Echeverry.

El boga Róbalo, trabajó después con José Manuel Palacios, comerciante que vivía en Puerto Echeverry y comercializaba entre Puerto Echeverry y Quibdó y viceversa, utilizando la ruta Puerto Echeverry-Berreberre-Chichiburrú-Istmo de Taridó-Río Taridó- Río San Pablo, Río Quito-Quibdó y viceversa.

La ruta era la siguiente: Río Dubaza-Río Berrebarre-Río Chichiburrú-Istmo de Taridó-Río Taridó-Río San Pablo-San Pablo arriba hacia el Tambo-Istmo El Tambo-Camino de herradura-Quebrada El Tambo-Istmina salida por Pueblo Nuevo.

Jornada: Puerto Echeverry-Taridó, 2 días; Taridó-El Tambo, 2 días. Descanso con los animales (cerdos) 3 días.

Róbalo tuvo varios hijos con la señora Librada, mucho de ellos aún están vivos y algunos viven aquí en Quibdó (conversación con Luis Neo Palacios, septiembre de 2014).

Personaje: Juan Pospó, 90 años vive en Pie de Pató
Narradora: profesora Genara Hurtado, 67 años

Juan Pospó es un hombre honesto, tolerante, respetuoso y paciente, como persona no tiene estudios, pero es una persona muy tratable, querido y delicado; así lo describe la profesora Genara, ella dice que viajó con Juan Pospó cuando era estudiante en Quibdó, el boga era el hombre de confianza de su padre Genaro Hurtado, quien durante todo el tiempo que se requirió el servicio de un boga el señor Juan Pospó fue su boga predilecto, al punto de confiarle la responsabilidad de llevar a su hija desde Pie de Pató hasta Quibdó; lo mismo sucedía con otros padres de familia quienes enviaban sus hijos e hijas bajo la tutoría del señor Juan Pospó.

Ruta: Pie de Pató-Istmo-Río Pató-Río Quito-Quibdó y viceversa; el tiempo de recorrido era de 3 días con el tiempo bueno; cuando estaba seco demoraba más por el arrastre y cuando crecía el río duraba más, hasta que el río estaba más seco. La ruta se hacía en tres jornadas. La profesora Genara dice que ella viajó con el señor Juan Pospó entre 1958 y la década de 1960, durante el tiempo que estudiaba en la ciudad de Quibdó. En esta época los bogas utilizaban palancas con recatón, canaletes; las canoas arrimaban por el puerto baulero en Quibdó y cuando llegaban al pie del camino en el río Pató, quedaban en el puerto de Juan Domingo, el papá de Abelino. La profesora Genara dice que su hermana Aidé, quien también es educadora, posee mayor información que ella sobre el señor Juan Pospó, debido a que la citada profesora hizo mayor contacto con la región y sus habitantes en su época de estudiante (Genara Hurtado, comunicación personal, septiembre de 2014).

Personaje Ciriaco Cabrera, vivía en Nauca, falleció a la edad de 80 años

Narrador: Justo Daniel Hinestroza, 64 años, nacido en alto Baudó

Según dice Justo Daniel, Ciriaco fue boga de varios comerciantes del Alto Baudó, entre los cuales se destaca el señor Guadalupe; desde el Baudó exportaban: arroz, plátano, caucho, cacao, damagua y cerdos. Desde Quibdó, llevaban azúcar, manteca, sal, queso y pescado seco entre otros.

Justo Daniel afirma que Ciriaco era un boga muy apetecido por las personas que requerían sus servicios; fue boga durante mucho tiempo, hasta que empezaron a usar los motores fuera de borda. El señor Ciriaco tuvo varios hijos en diferentes mujeres, una de las cuales tuvo trillizos.

La ruta para Quibdó, la hacían por Amparraidá y Pie de Pató. La de Amparraidá se hacía mediante el siguiente recorrido: Río Baudó-Quebrada Amparraidá-Istmo-Río Suruco-Río Munguidó-Río Atrato-Quibdó. La duración del viaje era de 5 a 8 días. El viaje se realizaba en canoas y se usaba palanca y canaletes (comunicación personal, con Justo Daniel Hinestroza, octubre de 2014).

Personajes: Juan Pospó (vivo), Joselito, José Irene y 


\section{Los bogas del Chocó. LA Lozano, LE Palacios}

Arcadio (fallecidos) y Angel Antonio (El Choclo)

Narrador Gumersindo Rivas Rentería, 66 años de edad, nacido en Pie de Pato, Alto Baudó.

Según afirma el entrevistado, estos señores fueron bogas muy responsables, personas de mucho fundamento en su trabajo, generalmente no dormían cuidando sus canoas. Estos bogas le hacían viajes a comerciante como Félix Cantalicio Romaña y Cenobia Mosquera, entre otros. Desde Pie de Pató, traían arroz, cacao y caucho. Los bogas eran veteranos, expertos en su materia, generalmente viajaban dos bogas, uno en la punta y otro en la patilla de la canoa, dice Gumersindo Rivas, además afirma nuestro entrevistado que a él también le hicieron viajes al igual que a su mamá Ofelia Rentería de Rivas, quienes también traían arroz, cacao y caucho desde Pie de Pató y desde Quibdó, llevaban mercancías como: manteca, azúcar, jabón, queso $\mathrm{y}$ otros productos.

La ruta: Pie de Pató-Istmo de Baudó-Pató-Río Pató-Río Quito-Quibdó y viceversa; el recorrido se hacía en tres o cuatro jornadas, sin embargo, cuando el río Pató se crecía, permanecían hasta tres días en una sola parte, esperando que secara (Gumersindo Rivas Rentería, comunicación personal, septiembre de 2014).

\section{Consideraciones finales}

Como conclusiones podemos afirmar que la fortaleza y capacidad de estos hombres bogas asumían con estoicismo los retos, las dificultades, los desafíos, los peligros y toda clase de contingencias que la fuerza de la naturaleza en este caso distanciaba las comunicaciones y las distintas formas de vida del hombre de esta región.
Son ellos pues, quienes con su bizarría fortaleza, ímpetu y vocación humana en el trasegar de los distintos ríos chocoanos unieron las tres cuencas más importantes que identifican el poblamiento de esta comarca tales como son la cuenca del Baudó, la cuenca del San Juan y la cuenca del Atrato.

Así se agilizó el comercio regional, se propició la comunicación escrita entre sus distintos pueblos llevando noticias unas veces negativas y propiciando albricias de índole positiva, utilizando fórmulas que si bien hoy en día son consideradas rudimentarias, para su momento y hasta la actualidad cumplieron un papel preponderante en la satisfacción de necesidades humanas que los estudios antropológicos, reconocen como un aporte y soporte de la estructura social y cultural del hombre del departamento del Chocó.

Los bogas constituyeron y constituyen parte fundamental del desarrollo hasta hoy alcanzado en este departamento, transportando también al elemento humano a los centros de mayor importancia sociales, culturales y educativos que ha tenido y tiene este departamento.

\section{Literatura citada}

Hust G. 2010. Los bogas de Colombia. Bogotá: Grupo de Estudios Afrocolombianos (GEA), Universidad de los Andes, Universidad Nacional de Colombia.

Madiedo MM.1873. El boga del Magdalena. En: Museo de cuadros de costumbres: variedades y viajes. Tomo I. Bogotá: Banco Popular: pp. 13-21

Noguera Mendoza A. 1982. Colombia bajo la sombra de sus árboles. Bogotá: Fondo Cultural Cafetero.

Samper JM. 1861. Ensayo sobre las revoluciones políticas y los problemas sociales. Bogotá: Editorial Centro. 